\title{
Risk factors of mortality in nine years of follow-up after dynamic cardiomyoplasty
}

Fatores determinantes de mortalidade em nove anos de seguimento pós cardiomioplastia dinâmica

\section{Abstract}

Purpose: To retrospectively evaluate the survival rate of patients that underwent dynamic cardiomyoplasty, determining the influence of pre-, intra- and post-operative factors and the evolution of left ventricle ejection fraction according to the stimulation mode.

Method: Forty-three patients that underwent dynamic cardiomyoplasty between May 1988 and September 1997 were analyzed. Functional class III was predominant $(81.4 \%)$. The mean left ventricle ejection fraction was $19.37 \pm 3.48 \%$. Hospital death was $2.2 \%$ and 39 patients who completed the conditioning period had a mean follow up of $46 \pm 26$ months. Twenty-eight patients were predominantly maintained under stimulation mode 1:1 and 11 under 1:2 stimulation mode.

Results: Survival rate at nine years of follow up was $9 \%$. The causes of death were progression of the heart failure and sudden cardiac death. Functional class, the pulmonary vascular-resistance index and stimulation mode were identified as risk factors. The maintenance of the increase of the left ventricle ejection fraction when compared to the preoperative values was more consistent during the studied period when the graft was stimulated in the 1:2 mode.

Conclusion: Late results of dynamic cardiomyoplasty are limited by the high incidence of deaths by progression of the heart failure and sudden cardiac death. Survival rate is influenced by the preoperative clinical condition and by the stimulation mode. Muscle graft performance is higher at late follow up with the 1:2 stimulation mode.

Descriptors: Cardiomyopathy. Cardiomyoplasty, risk factors, prognosis. Heart failure, surgery.

\section{Resumo}

Objetivo: Analisar, retrospectivamente, a sobrevivência dos pacientes submetidos a cardiomioplastia dinâmica, determinando a influência de fatores pré, intra e pósoperatório e o comportamento da fração de ejeção conforme o modo de estimulação.

Método: Foram analisados 43 pacientes submetidos a cardiomioplastia dinâmica, no período de maio de 1988 a setembro de 1997. A classe funcional III foi predominante

Work performed in the Instituto do Coração of the Hospital das Clínicas, Medical School, University de São Paulo.

1 - Surgery Department of the Instituto do Coração of the Hospital das Clínicas, Medical School, University de São Paulo.

Correspondence address: Anderson Benício. Instituto do Coração. Av Dr. Enéas de Carvalho Aguiar, $44-2^{\circ}$ andar. Divisão de Cirurgia Cardiopatias Gerais. São Paulo, SP, Brazil. CEP: 05403-000. Phone/ Fax: (11) 3069-5318.

e-mail: abenicio@uol.com.br 
$(81,4 \%)$. A fração de ejeção média do VE foi de $19,37 \pm 3,48 \%$. A mortalidade hospitalar foi de $2,2 \%$ e 39 pacientes, que completaram o período de condicionamento, tiveram seguimento médio de $46 \pm 26$ meses. Vinte e oito pacientes foram mantidos predominantemente sob estimulação em modo 1:1 e 11 pacientes foram mantidos predominantemente modo $1: 1$ e 11 pacientes foram

Resultados: A sobrevivência foi de $9 \%$ em nove anos. As causas de óbito foram progressão da insuficiência cardíaca e morte súbita. A classe funcional, o índice de resistência vascular pulmonar e o modo de estimulação foram identificados como fatores independentes de prognóstico. A manutenção da melhora da fração de ejeção do VE em relação ao pré-operatório foi

\section{INTRODUCTION}

Introduced by CARPENTIER \& CHACHQUES [1] in 1985 , dynamic cardiomyoplasty has as its objective a reversal of heart failure and to avoid the progression of the underlying disease by increasing the ventricular contractility and by reinforcing the ventricular walls. Although, it is performed in various centers, it has not been established as an alternative for heart transplantation, even though, it improves the ventricular function, the functional class and the capacity for physical effort [2-4], but it was limited to functional class III patients $[4,5]$. On the other hand, no increase in the long-term survival rate of these patients has been evidenced [6].

In a retrospective study, we described the determining factors of long-term survival of patients submitted to dynamic cardiomyoplasty. We analyzed the influence of preintra- and post-operative factors on the evolution over the long term and determined the correlation of these factors with the incidence of sudden death and with deaths due to progression of the heart failure or for the necessity of heart transplantation after dynamic cardiomyoplasty. Finally, we analyzed the ventricular function according to the stimulation mode applied to the great dorsal muscle.

\section{METHOD}

Forty-three patients with dilated cardiomyopathy were submitted to dynamic cardiomyoplasty in the Heart Institute of HCFMUSP, between May 1988 and September 1997. All the patients were suffering from heart failure and pulmonary hypertension. All the patients presented with progression of the disease despite of optimized pharmacotherapy. Patients using intravenous inotropic drugs were excluded as well as those with complex or clinically intractable arrhythmia, left ventricular chambers greater than $50 \mathrm{~mm} /$ mais consistente ao longo do período estudado, quando o enxerto muscular foi estimulado em modo 1:2.

Conclusão: Os resultados tardios da cardiomioplastia dinâmica são limitados pela alta incidência de morte súbita e de óbitos decorrentes da progressão da doença de base. A sobrevivência é influenciada pela condição clínica préoperatória e pelo modo de estimulação do enxerto. O desempenho do enxerto muscular é mais satisfatório a longo prazo quando submetido à estimulação modo 1:2.

Descritores: Miocardiopatia dilatada. Cardiomioplastia. Fatores de risco. Prognóstico. Insuficiência cardíaca, cirugia.

$\mathrm{m}^{2}$, significant pulmonary dysfunction (vital capacity less than 55\%), degenerative muscular disease, renal failure, hepatic failure, HIV infection, psychiatric disorders and alcoholism.

Thirty-four patients were male. The patients had a mean age of $44.9 \pm 9.4$ years ranging from 18 to 63 years old. Thirty-five patients were functional class III-NYHA and eighth patients were functional class IV. The hemodynamic data are shown in Table 1.

Table 1. Pre-operative laboratorial variables.

\begin{tabular}{ll}
\hline Variables & Mean \pm Standard deviation \\
\hline Ventriculography with Radioisotopes & \\
Left ventricular ejection fraction (\%) & $19,37 \pm 3,48$ \\
$\begin{array}{l}\text { Right ventricular ejection fraction (\%) } \\
\text { Doppler echocardiography }\end{array}$ & $24,33 \pm 6,32$ \\
Left ventricular diastolic diameter (mm) & $73,42 \pm 5,73$ \\
Left ventricular systolic shortening (\%) & $12,56 \pm 2,27$ \\
Right cardiac catheterism & \\
Right atrium mean pressure (mmHg) & $8,63 \pm 3,63$ \\
Pulmonary artery mean pressure $(\mathrm{mmHg})$ & $33,79 \pm 10,27$ \\
Pulmonary capillary mean pressure $(\mathrm{mmHg})$ & $23,09 \pm 6,15$ \\
Cardiac index $\left(1\right.$ min $\left.^{-1} \cdot \mathrm{m}^{-2}\right)$ & $1,98 \pm 0,75$ \\
Pulmonary vascular resistance (dina. sec $\left.{ }^{-1} \mathrm{~cm}^{-5}\right)$ & $266,48 \pm 155,70$ \\
\hline
\end{tabular}

Eight patients suffered from chronic atrial fibrillation and 26 suffered from non-sustained ventricular tachycardia before the operation. One patient suffered from moderate mitral valve failure and 17 from slight mitral valve failure as evidenced by 2-dimensional echocardiography. Cardiac catheterism demonstrated compromise of greater than $70 \%$ of the coronary arteries in two patients. 
The employed technique was according to that described by CHACHQUES et al. [7]. In three patients associated procedures were necessary: mitral annuloplasty in one patient and coronary artery bypass grafting in two patients; without the use of cardiopulmonary bypass.

Electrical stimulation of the muscle graft was also from the protocol described by CHACHQUES et al. [7], with initiation two weeks after the operation. In a later postoperative period, the stimulation of the muscle graft was synchronized to each heartbeat (1:1 mode) or to alternative heartbeats $(1: 2$ mode). Twenty-eight patients had their cardiac grafts stimulated predominately in 1:1 mode. Twenty of these patients were operated in functional class IV. Eleven patients had their muscle grafts stimulated predominantly in 1:2 mode, where all these patients were operated in functional class III.

The patients were studied at three-month intervals during the first year of follow up and after this at six-month intervals. All the patients continued with their usual medicines for heart disease.

Left and right ventricle function alterations in the postoperative period were investigated by radioisotopic angiography performed in the third, sixth, and twelfth postoperative months. During the second to fifth post-operative years of follow up, this control was performed annually.

With the objective of analyzing the influence of the pre, intra- and post-operative factors in the late follow up of these patients, the NYHA functional class, the left ventricle diastolic diameter (LVDD) and the systolic shortening of the of the left ventricle (SSLV) were evaluated by echocardiography. Also, using radioisotopic ventriculography the right ventricle ejection fraction (RVEF) and the left ventricle ejection fraction (LVEF) were assessed. In relation to the hemodynamic studies, the mean right atrium filling pressure (RAP), the mean pulmonary capillary pressure (PCP), mean pulmonary artery pressure (PAP), the pulmonary vascular resistance (PVR) and the cardiac index (CI) were analyzed. Finally, the presence of rhythms such as: atrial fibrillation or non-sustained ventricular tachycardia were assessed.

The intra-operative factors analyzed were the percentage of involvement of the grafted muscle around the free wall of the left and right ventricles and the presence of ischemia of the muscle graft. These were evidenced through the serum level of creatine phosphokinase (equal to or greater than $1500 \mathrm{UI}$ ) in the immediate post-operative period, associated with the absence of grafted muscle contractions, identified by palpation or through radioscopy. Additionally, the mode of the predominant synchronization utilized in muscle graft stimulation was analyzed.

In the analysis of the parameters related to survival, all the patients who died during the follow up period and also the patients who underwent heart transplantation were considered.

The mortality rate and rate of events that occurred during the follow up period were analyzed by the Kaplan-Meier method. The obtained curves were analyzed by means of the linear regression method. The association of pre-, intraand post-operative variables with the survival and morbid events were assessed by means of an isolated analysis of variables utilizing analysis of the Cox proportional risk. Variables with $p$-values of less than 0.10 by means of isolated analysis were submitted to multivariable analysis by degrees. The survival and event curves obtained from the variables considered as independent prognostic factors were compared by means of the log-rank test.

For the comparisons of the LVEF between the preoperative and other follow-up periods, studies were performed by means of analysis of the variance complemented by employing the Dunnet test and dual variance analysis of repeated measurements complemented by the Bonferroni test.

All the calculations were performed using the statistical analysis computer program SPSS for Windows 10.0. P-values $<0.05$ were considered significant.

\section{RESULTS}

There were three deaths during the immediate postoperative and graft conditioning periods. One was due to cardiogenic shock associated with pulmonary infection on about the twentieth post-operative day. Another presented with cardiogenic shock and localized infection with death on the 40th post-operative day and the third death occurred in the second post-operative month due to cardiogenic shock and pulmonary emboli.

In the same period, a patient in cardiogenic shock requiring an intra-aortic balloon due to a progression of the heart failure was submitted to orthotopic heart transplantation. Six patients presented with ischemia of the muscle graft and did not respond to the stimulation of a pulse generator (cardiomyostimulator).

The length of the post-operative follow up of the 39 patients who completed the muscle graft-conditioning period varied from 6 to 108 months, with a mean of 46.5 months and standard deviation of 28.8 months. Twenty-eight of these patients were maintained with grafted muscle stimulation at a 1:1 mode. Eleven patients were maintained with the graftedmuscle stimulation synchronized in an intercalated manner at each two heartbeats.

Twenty-nine patients died during the late follow up period. In 14 patients, death occurred due to progression of the heart failure. In 15, death was due to sudden death. Two patients were submitted to heart transplantation for 
progression of the heart failure in the 22nd and 26th months of follow up.

The survival curve shows indices of survival of $83.7 \%$ in the first year, $37.1 \%$ at five years and $9 \%$ at 9 years of follow up after dynamic cardiomyoplasty. Analysis of this curve demonstrates a pattern of exponential fall $\left(\mathrm{R}^{2}=0.99\right)$ Figure 1.

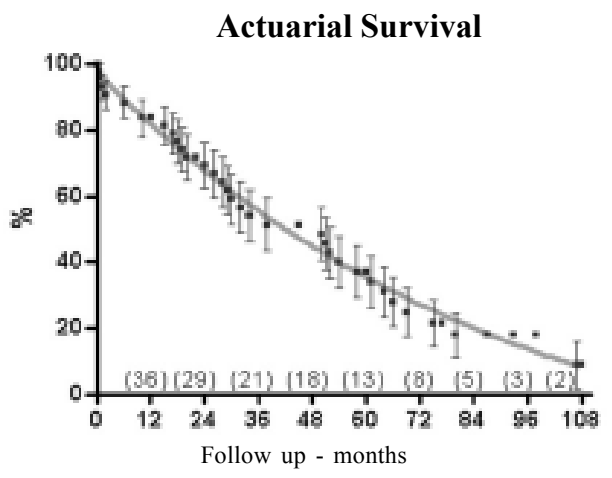

Fig. 1 - Actuarial survival curve (Kaplan-Meier) after dynamic cardiomyoplasty. The light-blue line represents the curve obtained by non-linear regression. The numbers in parenthesis indicate the number of patients in each study period.

Figure 2 shows the deaths related to progression of the heart failure and to sudden death. The incidence of death due to progression of the heart failure was slightly greater than for sudden death, mainly in the first years of follow up. The approximate incidence of mortality by sudden death was 8.2 events per patient-year. The correlation incidences $\left(\mathrm{R}^{2}\right)$ observed for the curves of mortality for heart failure and for sudden death were 0.96 and 0.95 respectively.

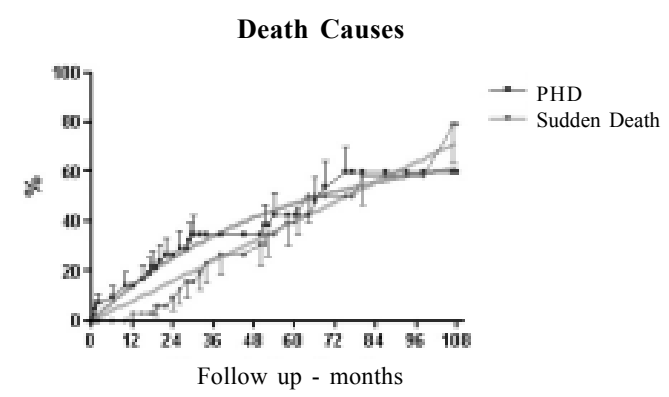

Fig. 2 - Curves of death rates by progressive heart disease (PHD) and by arrhythmia or sudden death in the post-operative follow up period after dynamic cardiomyoplasty. The light-colored lines represent the curves obtained by non-linear regression.
Table 2 shows the results of the isolated analysis of the pre- intra- and post-operative parameters associated with survival after dynamic cardiomyoplasty. The identified parameters were as follows: functional class, PAP, CI, PVR and stimulation mode.

Table 2. Individual analysis of the pre-, intra- and post-operative parameters related to the survival over 9 years of follow up after dynamic cardiomyoplasty. P-values $<0.05$ (asterisk) were considered significant.

\begin{tabular}{ll}
\hline Parameters & Significance \\
\hline Functional Class & $\mathrm{p}=0,0016^{*}$ \\
Left ventricular diastolic diameter & $\mathrm{p}=0,3392$ \\
Left ventricular diastolic volume & $\mathrm{p}=0,1144$ \\
Left ventricular ejection fraction & $\mathrm{p}=0,8927$ \\
Right ventricular systolic shortening & $\mathrm{p}=0,2973$ \\
Right atrium pressure & $\mathrm{p}=0,0692$ \\
Pulmonary capillary pressure & $\mathrm{p}=0,1049$ \\
Pulmonary arterial pressure & $\mathrm{p}=0,0242^{*}$ \\
Heart index & $\mathrm{p}=0,0225^{*}$ \\
Pulmonary vascular resistance & $\mathrm{p}=0,0024 *$ \\
Rhythm & $\mathrm{p}=0,0693$ \\
Non-sustained ventricular tachycardia & $\mathrm{p}=0,1108$ \\
Involvement of the graft on the right ventricle & $\mathrm{p}=0,3442$ \\
Ischemia of the graft & $\mathrm{p}=0,0693$ \\
Stimulation mode & $\mathrm{p}=0,0073 *$ \\
\hline
\end{tabular}

Evaluating only the pre-operative parameters, the functional class and the PVR were identified as independent prognostic factors, with p-values of 0.0053 and 0.0494 respectively.

When the analysis of the parameters associated with survival is made with the inclusion of post-operative variables, the functional class, PVR and the stimulation mode were identified as independent prognostic factors with $\mathrm{p}$ values of $0.0098,0.0123$ and 0.0424 respectively.

The survival curves obtained from the three prognostic factors are presented in Figures 3, 4 and 5.

In the analysis of pre-operative factors with deaths related to progressive heart disease the following risk factors were identified: functional class, RAP, PCP, PAP, CI, PVR and the stimulation mode (Table 3). However, only PAP and the functional class were identified as independent prognostic factors, with p-values of 0.0008 and 0.0498 respectively.

In the correlation of the pre-operative factors with deaths related to sudden death, only functional class was identified as statistically significant $(\mathrm{p}$-value $=0.0311-$ Table 4$)$. 


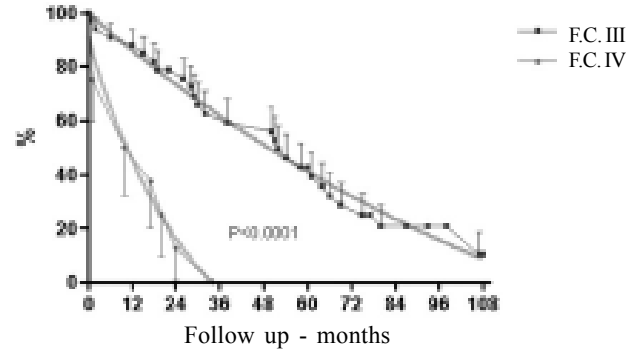

Fig. 3 - Actuarial survival curve (Kaplan-Meier) after dynamic cardiomyoplasty, according to the pre-operative functional class (FC). P-value was calculated by the log-rank test.

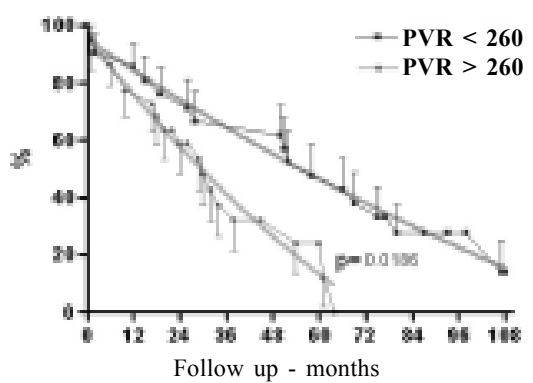

Fig. 4 - Actuarial survival curve (Kaplan-Meier) after dynamic cardiomyoplasty, according to the pulmonary vascular resistance level (PVR). P-value was calculated by the log-rank test.

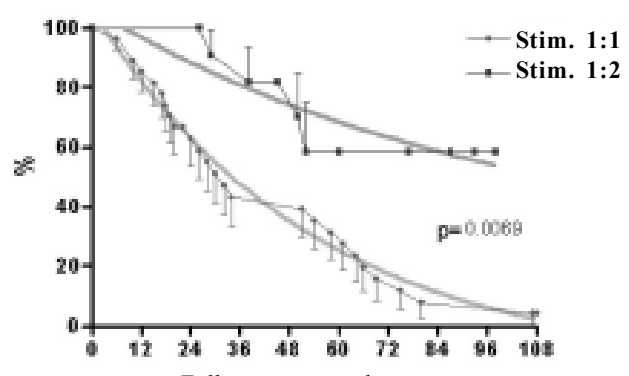

Follow up - months

Fig. 5 - Actuarial survival curve (Kaplan-Meier) after dynamic cardiomyoplasty, according to the stimulation mode. P-value was calculated by the log-rank test.
Table 3. Correlation of the pre-, intra- and post-operative factors with morbid events by progressive heart disease after dynamic cardiomyoplasty. P-values $<0.05$ (asterisk) were considered significant.

\begin{tabular}{ll}
\hline Parameters & Significance \\
\hline Functional Class & $\mathrm{p}=0,0021^{*}$ \\
Left ventricular diastolic diameter & $\mathrm{p}=0,0823$ \\
Left ventricular diastolic volume & $\mathrm{p}=0,0764$ \\
Left ventricular ejection fraction & $\mathrm{p}=0,9093$ \\
Right ventricular systolic shortening & $\mathrm{p}=0,1148$ \\
Right atrium pressure & $\mathrm{p}=0,0015^{*}$ \\
Pulmonary capillary pressure & $\mathrm{p}=0,0027^{*}$ \\
Pulmonary arterial pressure & $\mathrm{p}=0,0021^{*}$ \\
Heart index & $\mathrm{p}=0,0324^{*}$ \\
Pulmonary vascular resistance & $\mathrm{p}=0,0051^{*}$ \\
Rhythm & $\mathrm{p}=0,3218$ \\
Non-sustained ventricular tachycardia & $\mathrm{p}=0,543$ \\
Involvement of the graft on the right ventricle & $\mathrm{p}=0,5517$ \\
Ischemia of the graft & $\mathrm{p}=0,3218$ \\
Stimulation mode & $\mathrm{p}=0,0367 *$ \\
\hline
\end{tabular}

Table 4. Correlation of the pre-, intra- and post-operative factors with morbid events by sudden death or arrhythmia after dynamic cardiomyoplasty. P-values $<0.05$ (asterisk) were considered significant.

\begin{tabular}{ll}
\hline Parameters & Significance \\
\hline Functional Class & $\mathrm{p}=0,0311^{*}$ \\
Left ventricular diastolic diameter & $\mathrm{p}=0,5730$ \\
Left ventricular diastolic volume & $\mathrm{p}=0,9568$ \\
Left ventricular ejection fraction & $\mathrm{p}=0,8497$ \\
Right ventricular systolic shortening & $\mathrm{p}=0,7771$ \\
Right atrium pressure & $\mathrm{p}=0,5941$ \\
Pulmonary capillary pressure & $\mathrm{p}=0,4174$ \\
Pulmonary arterial pressure & $\mathrm{p}=0,9954$ \\
Heart index & $\mathrm{p}=0,4639$ \\
Pulmonary vascular resistance & $\mathrm{p}=0,1991$ \\
Rhythm & $\mathrm{p}=0,1597$ \\
Non-sustained ventricular tachycardia & $\mathrm{p}=0,0908$ \\
Involvement of the graft on the right ventricle & $\mathrm{p}=0,3816$ \\
Ischemia of the graft & $\mathrm{p}=0,1597$ \\
Stimulation mode & $\mathrm{p}=0,1835$ \\
\hline
\end{tabular}

Figure 6 shows the evaluation of the LVEF over five years of follow up. Twenty-two patients who completed at least 36 months of follow-up were included in this study. 


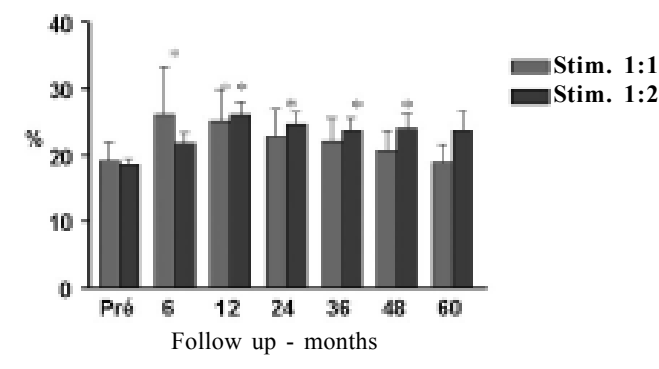

$*=\mathrm{p}<0.05$ in relation to the pre-operative period

Fig. 6 - Analysis of the ejection fraction using radioisotopic angiography in the pre-operative period until five years offollow up.

The patients were divided in two groups: one group (12 patients) where the patients' grafts were predominantly stimulated in the 1:1 mode; and another group (10 patients) where the patients' grafts were predominantly stimulated in the $1: 2$ mode.

In the 1:1 mode group, the LVEF increased significantly from $19.2 \% \pm 2.8 \%$ in the pre-operative period to $26.0 \% \pm$ $7.28 \%$ at six months of follow up (p-value $<0.05$ ). However, this increase in ejection fraction was maintained in a significant form only for the first year of follow up, after which a drop in the values of these parameters was observed until the end of the five year follow up period.

In the group of patients who were maintained stimulated in the 1:2 mode, an improvement of the ejection fraction started to be significant only from the end of the first year of follow up $(26.0 \% \pm 16.0 \%)$, when compared with the preoperative period $(18.5 \% \pm 3.11 \%)$ ( $p$-value $<0.005)$.

Different to the group under 1:1 stimulation, in this group the LVEF remained significantly greater than the preoperative levels until the fourth post-operative year.

Nevertheless, when these data were analyzed, the differences of the LVEF between the two groups was not observed to be statistically significant ( $p$-value $=0.1904$ ).

\section{COMMENTS}

This study showed that the evolution of patients suffering from dilated cardiomyopathies submitted to dynamic cardiomyoplasty was characterized by a high mortality rate over the long term, despite of the positive impact of the procedure on the improvement of the ventricular function. The main causes of mortality were: progression of the underlying disease and sudden death. Also, the long-term survival after cardiomyoplasty was limited by the clinical condition of the patient in the preoperative period (NYHA functional class), by the pulmonary vascular resistance and the stimulation mode.

In the initial phase of dynamic cardiomyoplasty, survival was influenced by high hospital death, except in some initial experiments in which there was no hospital death, characterizing the surgical procedure as of low risk. Only later in multicenter studies, was it possible to confirm the low risk of this procedure, showing better survival rates in the first years of the post-operative period $[6,8,9]$.

According to data from the Medtonic Database, the mortality during phases I and II were of $31 \%$ and $12 \%$ respectively $[6,10]$. In the C-SMART multicenter study [11] the mortality was $3 \%$. This variation in the death rate was a consequence of the improved knowledge of the mechanism of the action of dynamic cardiomyoplasty and of the better selection of the patients.

The main causes of mortality after dynamic cardiomyoplasty are related to the progression to heart failure and by arrhythmic events. Besides functional class IV, LVEF less than $15 \%$, the number of coronary arteries with lesions equal to or greater than $70 \%$ and low chronotropic response during exercise were identified as independent risk factors for immediate post-operative death [12].

In several concurrent experiments, functional class IV and LVEF less than 20\% [3], severe biventricular dysfunction, pulmonary vascular hypertension, respiratory failure, associated operative procedures and the prophylactic use of intra-aortic balloon $[13,14]$ were also considered independent risk factors in hospital mortality.

Although the presence of arrhythmia in the postoperative period has not been considered as an independent risk factor, in phase II of the Medtronic study [6], this factor was associated to death during the immediate post-operative period and during the muscle graft conditioning phase. It was also related to mortality due to sudden death and progression of the heart failure $[6,8,15]$.

Operative manipulation of the skeletal muscle graft with lesions caused during dissection, demonstrated by the high serum levels of creatine phosphokinase, is also related to high mortality in the post-operative period [16]. Over the last years, the significant reduction in hospital mortality has been due to the better selection of patients, the elimination of cardiopulmonary bypass and of procedures associated to an improved management of intensive therapy in the immediate post-operative period [17].

There is evidence that improvement of left ventricular function is related to the direct action of the grafted muscle contraction on the ventricular chambers synchronized with the heartbeat and the effect of elastic containment promoted by the involvement of grafted muscle around the ventricular walls. These are the main mechanisms of cardiomyoplasty. Both mechanisms act to improve the diastolic ventricular 
function and, especially, in the reduction of stress on the ventricular wall, contributing to the re-establishment of the myocardial balance of oxygen and the reversal of the remodeling process [18]. An improvement of the left ventricular function has been reported by several authors in clinical and experimental studies, in which the LVEF gained increases of $15 \%$ to $40 \%$ compared to the pre-operative LVEF, in six months of follow up $[5,9,19\}$.

The improved hemodynamic parameters observed after dynamic cardiomyoplasty [2] have been attributed not only to the direct action of the contraction of the muscle graft, but also to the effect of the elastic containment over the ventricular chambers. This was evidenced in comparisons of results obtained by turning on and turning off the cardiomyostimulator [19,20]. In this study, there was a significant increase of the systolic volume and of the LVEF of approximately $20 \%$ to $30 \%$, with the stimulated muscle graft.

However, other experiments did not demonstrate any real benefit of the hemodynamic parameters due to muscle graft contraction after dynamic cardiomyoplasty, suggesting that the effect of elastic containment is the main mechanism of the action, avoiding additional dilation of the heart chambers and stabilizing the process of heart failure [21] Other reports corroborated showing the effect of passive containment, contributing to the reversal of the remodeling process as well as improving the diastolic function in a short period of time after dynamic cardiomyoplasty [22-24].

A strong influence of the stimulation mode on the left ventricular performance was observed. In patients in whom the graft stimulation was synchronized in 1:1 mode, the LVEF had a significant increase in relation to the pre-operative values within six post-operative months, increased until 12 months of follow up, and was maintained until the second post-operative year. On the other hand, in patients who had their grafts stimulated in the 1:2 mode, the LVEF did not present with a significant increase in relation to the preoperative values during the first year of follow up. However, after the first year, the LVEF became significantly greater in relation to the pre-operative values, and was maintained until the fourth post-operative year after dynamic cardiomyoplasty.

The survival rate at five years after dynamic cardiomyoplasty is presented in only two series which gave conflicting results. CHACHQUES et al. [24] reported the probability of surviving for seven years of follow up of $54 \%$, whilst MOREIRA et al. [25] reported a rate of $23 \%$ in the same period. The main causes of death during the late follow up period after dynamic cardiomyoplasty are heart failure, and sudden death, although arrhythmia was not correlated to the severity of ventricular dysfunction [4]. In this study we present a survival rate of $9 \%$ in a follow up period of nine years. Sudden death and progression of the heart failure were the main causes of death. Age greater than 65 years old, the technique of cardiac suturing associated to the repair of the mitral valve or coronary artery bypass grafting, pulmonary hypertension, hemodynamic instability, pre-operative functional class, severe biventricular dysfunction and pulmonary dysfunction were all considered to be independent risk factors [14]. The South American multicenter study demonstrated that the longterm survival rate was also significantly affected in preoperative functional class IV patients and by the pulmonary vascular resistance [8]. In late results, BRAILE et al. [26] demonstrated that patients who suffered from chagasic heart diseases did not present with a good long-term evolution when submitted to dynamic cardiomyoplasty, suggesting that patients with this etiology should be contraindicated for this procedure.

In relation to sudden death, atrial fibrillation and low right ventricular ejection function were isolated as independent risk fractions in the second phase of the Medtronic study [6]. However, in the analysis of mortality, the presence of arrhythmia in the pre-operative period was characterized as a risk factor, not only for sudden death but also for the global death rate.

In this study, the pre-operative functional class, the pulmonary vascular resistance and the muscle graft stimulation mode were identified as independent risk factors in the long-term survival rate after dynamic cardiomyoplasty. In particular the latter showed to be extremely important in determining early degenerative alterations in the structure of the skeletal muscle graft, and so compromising its performance in the long-term follow up.

This alteration in the performance of the skeletal muscle graft was observed from the change in our stimulation mode protocol from 1:1 to 1:2. In our initial experience, we observed two types of structural compromise of the skeletal muscle graft: significant atrophy and fibrosis and a significant reduction in the thickness of the skeletal muscle graft associated or not with lipid infiltration [25].

Lipid infiltration normally occurs in patients that present with ischemic compromise of the skeletal muscle graft in the immediate post-operative period. It is important to stress that this complication was more common in patients who had their muscle grafts stimulated at each heartbeat (1:1), which was seen at the beginning of our experience. Such complications were not as evident in other series in which the muscle graft was synchronized in a 1:2 mode [4]. This occurrence, also reported by other authors [14], was associated with a high mortality rate in the late follow up period, mainly due to progression of the heart failure.

Dynamic cardiomyoplasty did not correspond to the expectations during the initial development of the technique, 
although it has demonstrated relevant results and a strong impact on the surgical treatment of heart failure. In the initial period, the patients were submitted to dynamic cardiomyoplasty in functional classes III and IV. Additionally, all the patients had their skeletal muscle grafts stimulated synchronized to the heartbeat (1:1). In a later phase, cardiomyoplasty was only indicated for functional class III patients and the skeletal muscle graft started to be stimulated in the 1:2 mode. This alteration improved the evolution of patients, mainly from the moment in which the pre-operative class started to be considered as an independent risk factor [25].

Dynamic cardiomyoplasty still represents a promising technique in the surgical treatment of heart failure. It improves the functional class, limits the remodeling process and stabilizes the progression to heart failure. Implantation of an automatic defibrillator might be effective to increase the long-term survival rate of the patients with high risk of sudden death. There have been no large series or even comparative studies, however, which determine the rea influence of defibrillators in relation to sudden death or its real impact on the long-term survival of these patients [27]. Technological advances in the development of new cardiomyostimulators [28], new stimulation modes and skeletal muscle graft preservation techniques [29-31] represent new perspectives in the establishment of dynamic cardiomyoplasty as a surgical treatment in patients with dilated cardiomyoplasty.

In conclusion, the long-term clinical evolution of patients with dilated cardiomyopathy who are submitted to dynamic cardiomyoplasty is limited by a high mortality rate by sudden death or by progression of the heart disease. The long-term survival rate is influenced by the pre-operative function class and pulmonary vascular resistance and by the stimulation mode in the post-operative period. The improvement in the left ventricular ejection fraction was more satisfactorily maintained when the skeletal muscle graft contractions were synchronized at a 1:2 rate in relation to the heartbeats.

\section{BIBLIOGRAPHIC REFERENCES}

1. Carpentier A, Chachques JC. Myocardial substitution with stimulated skeletal muscle: first successful clinical case. Lancet 1985; 1:1267.

2. Moreira LF, Bocchi EA, Stolf NA, Pileggi F, Jatene AD. Current expectations in dynamic cardiomyoplasty. Ann Thorac Surg 1993; 55: 299-303.

3. Carpentier A, Chachques JC, Acar C, Relland J, Mihaileanu S, Bensasson D et al. Dynamic cardiomyoplasty at seven years. J Thorac Cardiovasc Surg 1993; 106:42-54.
4. Moreira LF, Stolf NA. Dynamic cardiomyoplasty as a therapeutic alternative: current status. Heart Fail. Rev. 2001; 6:201-12.

5. Moreira LF, Stolf NA, Bocchi EA, Bacal F, Pego-Fernandes $\mathrm{PM}$, Abensur $\mathrm{H}$ et al. Clinical and left ventricular function outcomes up to five years after dynamic cardiomyoplasty. J Thorac Cardiovasc Surg 1995; 109:353-63.

6. Furnary AP, Chachques JC, Moreira LFP, Grunkemeier GL, Swanson JS, Stolf $\mathrm{N}$ et al. Long-term outcome, survival analysis, and risk stratification of dynamic cardiomyoplasty. J Thorac Cardiovasc Surg 1996; 112:1640-50.

7. Chachques JC, Grandjean PA, Carpentier A. Latissimus dorsi dynamic cardiomyoplasty. Ann Thorac Surg 1989; 47:600-4

8. Moreira LF, Stolf NA, Braile DM, Jatene AD. Dynamic cardiomyoplasty in South America. Ann Thorac Surg 1996; 61:408-12.

9. Furnary AP, Jessup M, Moreira LF. Multicenter trial of dynamic cardiomyoplasty for chronic heart failure. The American Cardiomyoplasty Group. J Am Coll Cardiol 1996; 28:1175-80.

10. Acker MA. Dynamic cardiomyoplasty: at the crossroads. Ann Thorac Surg 1999; 68:750-5.

1. Young JB, Kirkling JK. Cardiomyoplasty: skeletal muscle assist randomized trial (C-Smart): 6 month results (Abstract). Circulation 1999; 100:1514.

12. Rector TS, Benditt D, Chachques JC, Chiu RC, Delahaye F, Jessup $\mathrm{M}$ et al. Retrospective risk analysis for early heartrelated death after cardiomyoplasty. J Heart Lung Transplant 1997; 16:1018-25.

13. Tasdemir O, Küçükaksu SD, Vural KM, Katircioglu FS, Kütük E, Bayazit K. A comparison of the early and midterm results after dynamic cardiomyoplasty in patients with ischemic or idiopathic cardiomyopathy. J Thorac Cardiovasc Surg 1997; 113:173-81.

14. Chachques JC, Berrebi A, Hernigou A, Cohen-Solal A, Lavergne $\mathrm{T}$, Marino JP et al. Study of muscular and ventricular function in dynamic cardiomyoplasty: a ten-year follow-up. J Heart Lung Transplant 1997; 16:854-68.

15. Magovern GJ, Simpson KA. Clinical cardiomyoplasty: review of ten-year United States experience. Ann Thorac Surg 1996; 61:413-9.

16. Moreira LF, Stolf NA, Bocchi EA, Pereira-Barretto AC, Meneghetti JC, Giorgi MC et al. Latissimus dorsi cardiomyoplasty in the treatment of patients with dilated cardiomyopathy. Circulation 1990; 82(suppl IV):IV-257-63. 
17. Moreira LF, Seferian Jr P, Bocchi EA, Pego-Fernandes PM, Stolf NA, Pereira-Barretto AC et al. Survival improvement dynamic cardiomyoplasty in patients with dilated cardiomyopathy. Circulation 1991; 84(suppl V):III296- 302).

18. Bocchi EA, Moreira LFP, Moraes AV, Bellotti G, Gama M, Stolf NA et al. Effects of dynamic cardiomyoplasty on regional wall motion, ejection fraction, and geometry of left ventricle. Circulation 1992; 86(suppl V):II-231-5.

19. Jatene AD, Moreira LF Stolf NA, Bocchi EA, Seferian Jr. P, Fernandes PM et al. Left ventricular function changes after cardiomyoplasty in patients with dilated cardiomyopathy. J Thorac Cardiovasc Surg 1991; 102:132-9.

20. Tasdemir O, Vural KM, Küçükaksu SD, Tarcan OK, Ozdemir M, Kutuk E et al. Comparative study on cardiomyoplasty patients with the cardiomyostimulator on versus off. Ann Thorac Surg 1996; 62:1708-13.

21. Hagège AA, Desnos M, Fernandez F, Besse B, Mirochnik N, Castaldo $\mathrm{M}$ et al. Clinical study of the effects of latissimus dorsi muscle flap stimulation after cardiomyoplasty. Circulation 1995; 92(suppl 9):II-210-5.

22. Kass DA, Baughman KL, Pak PH, Cho PW, Levin HR, Gardne $\mathrm{TJ}$ et al. Reverse remodeling from cardiomyoplasty in human heart failure: external constraint versus active assist. Circulation $1995 ; 91: 2314-8$.

23. Lorusso R, Milan E, Volterrani M, Giubbini R, van der Veen FH, Schreuder JJ et al. Cardiomyoplasty as an isolated procedure to treat refractory heart failure. Eur J Cardiothorac Surg 1997; 11:363-72.
24. Chachques JC, Marino JP, Lajos P, Zegdi R, D'Attellis N, Fornes $\mathrm{P}$ et al. Dynamic cardiomyoplasty: clinical follow-up at 12 years. Eur J Cardiothorac Surg 1997; 12:560-8.

25. Moreira LFP, Stolf NAG, Bocchi EA, Bacal F, Pêgo-Fernande PM, Fiorelli AI et al. Evolução clínica e comportamento d função ventricular no pós-operatório tardio da cardiomioplastia. Rev Bras Cir Cardiovasc. 1995; 10:3-17.

26. Braile DM, Godoy MF, Thevenard GH, Thevenard RS, Braile MC, Leal JC et al. Dynamic cardiomyoplasty: long-term clinical results in patients with dilated cardiomyopathy. Ann Thorac Surg 2000; 69:1445-7.

27. Lorusso R, Marchini A, Bianchetti F, Curnis A, Visioli O, Zogno M. Cardiomyoplasty and implantable cardioverter defibrillator: efficacy and safety of concomitant device implantation: sudden death and cardiomyoplasty. J Card Surg 1998; 13:150-5.

28. Chekanov VS, Chachques JC, Brum F, Arzuaga J, Arzuaga P, Krum DP et al. LD-PACE II: a new cardiomyostimulator for cardiac bioassist. ASAIO J 2001; 47:50-5.

29. Kashem A, Santamore WP, Chiang B, Unger L, Ali AT, Slate AD. Vascular delay and intermittent stimulation: keys to successful latissimus dorsi muscle stimulation. Ann Thorac Surg 2001; 71:1866-73

30. Woo EB, Tang AT, Jarvis JC, Hasleton PS, Salmons S, Hooper TL. Improved viability of latissimus dorsi muscle grafts after electrical prestimulation. Muscle Nerve 2002; 25:679-84.

31. Rigatelli G, Carraro U, Barbiero M, Zanchetta M, Dimopoulos $\mathrm{K}$, Cobelli $\mathrm{F}$ et al. Activity-rest stimulation protocol improve cardiac assistance in dynamic cardiomyoplasty. Eur J Cardiothorac Surg 2002; 21:478-82. 